\title{
Contribuição ao estudo da desertificação na Bacia do Taperoá ${ }^{1}$
}

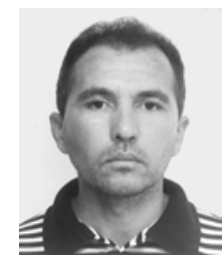

Bartolomeu I. de Souza1, Alain M. B. P. de Silans ${ }^{2} \&$ José B. dos Santos ${ }^{1}$

1 PRODEMA-UFPB. CEP 58050-900, João Pessoa, PB. Fone/Fax (83) 216-7472. E-mail: barto@jampa.com.br (Foto)

${ }^{2}$ DTCC/CT/UFPB. CEP 58059-900, João Pessoa, PB. Fone/Fax (83) 216-7684. E-mail: alain@lrh.ct.ufpb.br

Protocolo $102-22 / 7 / 2002$ - Aprovado em 12/2/2004

\begin{abstract}
Resumo: O fenômeno da desertificação na região semi-árida do Nordeste do Brasil é estudado a partir da análise de variáveis representativas do clima, vegetação, solos e aspectos socioeconômicos na bacia hidrográfica do Taperoá, no Estado da Paraíba - Brasil. As séries temporais da precipitação anual de 32 pluviômetros foram examinadas e um mapa de tendência da pluviosidade anual foi traçado. As variáveis mencionadas acima são estimadas para os municípios de São João do Cariri e Cabaceiras, respectivamente. Os resultados mostram, de modo diferenciado para os dois municípios, a susceptibilidade à desertificação. No primeiro município, todas as variáveis analisadas contribuem para afirmar que um processo bastante significativo de desertificação está em curso, inclusive associado a uma diminuição das precipitações anuais.
\end{abstract}

Palavras-chave: semi-árido, degradação, tendência de chuvas

\section{Contribution to study of desertification in the Taperoá Basin}

\begin{abstract}
The phenomenon of desertification in the semi-arid region of Northeast Brazil is studied from the analysis of some variables representative of climate, vegetation, soils and some economic and social aspects in the Taperoá Basin in the State of Paraíba, Brazil. Annual rainfall data from 32 rain gauges was treated by temporal series analysis and a trend map was drawn. All the above listed variables were estimated for São João do Cariri and Cabaceiras districts. Results show a diferent mode of susceptibility to desertification for both districts, especifically, in the São João do Cariri district, all the variables treated in this study contributed to the occurrence of a desertification process including a negative trend in annual rainfall.
\end{abstract}

Key words: semi arid, degradation, rain falltrend

\section{INTRODUÇÂO}

Atribui-se a criação do termo "desertificação" a Aubreville (1949) para caracterizar aquelas áreas que estavam ficando parecidas com desertos ou desertos que se estavam expandindo; posteriormente, muitos estudiosos a atribuíram ora a processos naturais, ora a processos induzidos pelo homem. Longe de ser puramente acadêmica, esta polêmica teve, e ainda tem, importância prática significativa, pois pode influenciar tanto na formação de políticas como na destinação de investimentos para combater este processo.

Ainda hoje diferentes correntes de opinião questionam a ocorrência concreta dos processos de desertificação. Do ponto de vista prático, no entanto, tal polêmica foi resolvida quando da negociação do documento da Agenda 21 e da Convenção das Nações Unidas de Combate à Desertificação (1995), em que esses processos foram atribuídos, simultaneamente, a atividades humanas (mau manejo dos recursos naturais) e a fatores climáticos nas zonas secas, caso em que a degradação da terra nesses ambientes deve ser entendida como a redução ou perda da produtividade biológica ou econômica provocada pela deterioração dos solos, dos recursos hídricos e da biodiversidade, resultando na diminuição da qualidade de vida da população afetada.

A definição de aridez para fins de aplicação no Plano de Ação de Combate à Desertificação, elaborado pelas Nações Unidas, baseou-se na metodologia desenvolvida por Thornthwaite (1941), com posterior ajustamento por Penman (1953), quando o índice de aridez (IA) de uma região depende da quantidade de água advinda da chuva (P) e da 
evapotranspiração potencial (ETP). As classes de variação para este índice são apresentadas na Tabela 1, a seguir:

Tabela 1. Classificação em função do índice de aridez (IA)

\begin{tabular}{cc}
\hline Classificação & IA \\
\hline Hiper-árido & $<0,05$ \\
Árido & $0,05<0,20$ \\
Semi-árido & $0,21<0,50$ \\
Sub-úmido seco & $0,51<0,65$ \\
Sub-úmido e Úmido & $>0,65$ \\
\hline
\end{tabular}

Para as áreas de aplicação da Convenção, o índice de aridez varia de 0,21 a 0,65 .

No Brasil, a sobrexploração dos recursos naturais, principalmente na zona semi-árida, tida como ambiente ecologicamente instável e de forte ação antrópica (Ab'Saber, 1977), faz com que esta região seja considerada bastante susceptível à desertificação. Segundo Conti (1995), os processos de circulação atmosférica predominantes nessa região podem contribuir também de modo significativo para a desertificação.

Este trabalho apresenta um estudo da desertificação realizado na bacia hidrográfica do Rio Taperoá, no Estado da Paraíba, no Nordeste do Brasil, situada na região semi-árida denominada "Cariris Velhos", onde a exploração econômica vem desequilibrando o sistema ambiental, de maneira intensiva.

\section{MATERIAL E MÉTODOS}

\section{Descrição da bacia hidrográfica do Rio Taperoá}

A bacia hidrográfica do Rio Taperoá está situada na parte central do Estado da Paraíba, na região do Cariri, e se localiza entre as coordenadas geográficas $6^{\circ} 51^{\prime} 31^{\prime \prime}$ e $7^{\circ} 34^{\prime} 21^{\prime \prime}$ de latitude sul e $36^{\circ} 0^{\prime} 55^{\prime \prime}$ e $37^{\circ} 13^{\prime} 9^{\prime \prime}$ ' de longitude oeste (Figura 1). O Taperoá, principal rio da bacia, de regime intermitente, nasce na Serra do Teixeira e desemboca no Rio Paraíba, no açude Boqueirão. A bacia do Rio Taperoá drena uma área de $5.667,49 \mathrm{~km}^{2}$ e seu perímetro é de $435,75 \mathrm{~km}$, estando inserida, segundo o método de Koeppen (1948), numa região semi-árida quente, devido as médias pluviométricas baixas $\left(<400 \mathrm{~mm} \mathrm{ano}^{-1}\right)$ e temperaturas médias mensais sempre superiores a $18^{\circ} \mathrm{C}$. Nesta região, observa-se que a maior concentração do total precipitado ocorre em um período aproximado de dois a quatro meses (janeiro a abril), correspondendo a $65 \%$ da pluviosidade anual.

Quanto à temperatura, a média anual é de $24^{\circ} \mathrm{C}$, com um máximo em novembro/dezembro $\left(28^{\circ} \mathrm{C}\right)$ e um mínimo em julho/ agosto $\left(21^{\circ} \mathrm{C}\right)$.

Os dados climatológicos da estação de Ouro velho (município de Sumé), medidos no tanque Classe A, apresentam-se bastante representativos para esta região (Tabela 2), onde se confirmam a pequena pluviosidade e os elevados níveis de temperatura, evaporação e evapotranspiração, tanto mensal como anualmente.

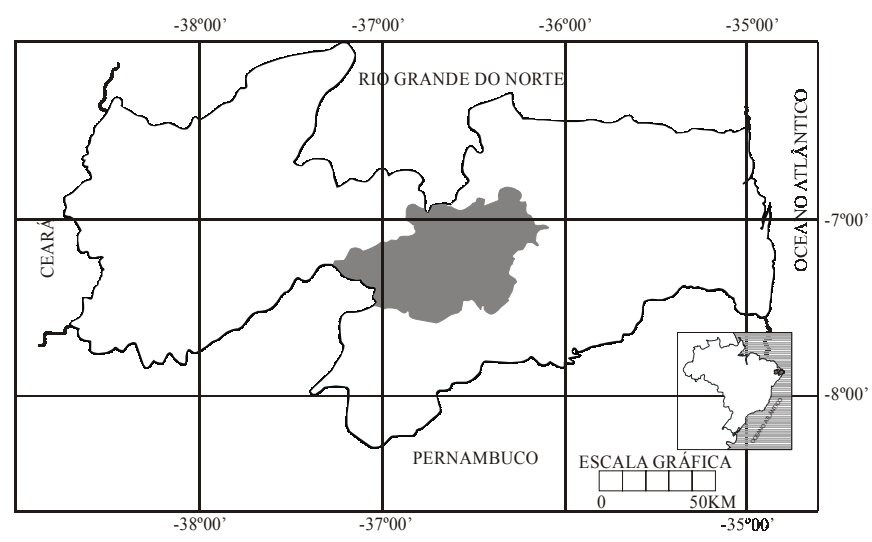

Figura 1. Localização da bacia do Rio Taperoá

A vegetação é praticamente uniforme, sendo a caatinga, tipo regional de savana estépica (IBGE, 1991), a formação natural predominante apresentando-se, às vezes, baixa e densa, outras vezes baixa e esparsa (Souza, 1999). As áreas desmatadas e utilizadas para a agricultura são, em geral, ocupadas pelas culturas de palma forrageira, agave e algodão, além de milho e feijão, representando uma pequena área da bacia; a pedologia é mais variada, englobando vários tipos de solo, todos pouco espessos, cascalhentos ou pedregosos.

Os municípios inseridos na bacia (total ou parcialmente) perfazem o total de 19, conferindo-lhe uma população de 102.235 habitantes, conforme o Censo Demográfico/PB (1991).

Na bacia hidrográfica do Rio Taperoá não existem projetos de irrigação significativos. A água dos açudes é usada principalmente para o abastecimento da população, enquanto as águas subterrâneas são pouco abundantes, ocorrendo de modo esparso em pequenas falhas no substrato cristalino ou no leito de rios e riachos possuindo, em geral, alto teor de salinidade.

\section{Metodologia}

Para o desenvolvimento deste trabalho, o plano de estudos apoiou-se em quatro eixos: climático, biológico, hidropedológico e socioeconômico, uma vez que, para se compreender a desertificação em sua totalidade, deve haver uma abordagem multidisciplinar e, sendo assim, a metodologia tomou a seguinte seqüência:

1. No eixo climático as séries temporais dos totais anuais precipitados foram estudadas através de uma análise de

Tabela 2. Dados climatológicos* da bacia do Rio Taperoá (Estação Ouro Velho)

\begin{tabular}{|c|c|c|c|c|c|c|c|c|c|c|c|c|}
\hline & Jan & Fev & Mar & Abr & Mai & Jun & Jul & Ago & Set & Out & Nov & Dez \\
\hline $\mathrm{T}^{\circ} \mathrm{C}$ & 26,0 & 24,5 & 24,0 & 23,5 & 22,5 & 22,0 & 21,0 & 22,0 & 23,5 & 25,0 & 26,0 & 27,0 \\
\hline $\mathrm{E}(\mathrm{mm})$ & 288,3 & 232,4 & 254,2 & 243,0 & 220,1 & 177,0 & 201,5 & 244,9 & 258,0 & 282,1 & 291,0 & 291,4 \\
\hline $\mathrm{P}(\mathrm{mm})$ & 43,8 & 77,4 & 132,9 & 130,2 & 58,6 & 42,4 & 23,4 & 9,2 & 5,0 & 6,4 & 11,9 & 18,1 \\
\hline ETP $(\mathrm{mm})$ & 173,6 & 124,8 & 117,8 & 114,0 & 108,5 & 108,0 & 120,9 & 145,7 & 159,0 & 176,7 & 174,0 & 182,9 \\
\hline
\end{tabular}

* T- Temperatura; E- Evaporação; P- Precipitação; ETP- Evapotranspiração potencial (Hargreaves, 1973) 
tendência e de periodicidade e analisados os dados de 32 postos pluviométricos dos estados da Paraíba, PB, Pernambuco, PE, e Rio Grande do Norte, RN, 13 deles localizados totalmente na bacia do Rio Taperoá, PB, e mais 19 em áreas adjacentes, servindo estes últimos para dar uma visão complementar à área que envolve a bacia hidrográfica em estudo.

Os dados de algumas séries não foram preenchidos, uma vez que tal preenchimento poderia falsificar os resultados, tendo em vista a diversificação de comportamento dos diversos postos considerados, em relação à análise de tendências, mesmo sendo na mesma região geográfica. De qualquer forma, as referidas falhas foram de pouca expressão. No caso específico do posto de Cabaceiras, os totais anuais precipitados no período de 1946 a 1959 foram muito baixos (SUDENE, 1990). Valores similares neste período, foram também encontrados em outro posto (Posto Bodocongó, situado a $30 \mathrm{~km}$ ), e se sabe de uma seca que se estendeu de 1953 a 1955; no entanto, Jacon (1982), a partir de um estudo detalhado das fichas dos observadores locais, atribui esses valores baixos a um provável erro relacionado à vedação da torneira do pluviômetro. Neste trabalho, esses dados não foram considerados.

A tendência das séries pluviométricas observadas deve ser entendida, segundo Geiger et al. (1974) como "a função valor médio de seu processo gerador", podendo ser crescente, decrescente ou estacionária indicando, portanto, mudanças no comportamento climático regional (Conti, 1995).

Considerando-se que na região estudada os valores do coeficiente de variação das precipitações anuais são muito elevados, o que confere, a este ecossistema, forte vulnerabilidade (Silans et al., 1999), efetuou-se uma suavização desses dados para diminuir as disparidades, através da utilização de médias móveis de 3 e 5 anos, além de se observar as tendências do quadrimestre mais chuvoso.

A fim de se traçar o mapa das tendências de precipitação, procurou-se verificar a coerência do valor obtido, observandose simultaneamente os quatro valores de tendência calculados (anual, quadrimestral, média móvel de 3 anos e média móvel de 5 anos), levando-se em conta que esta poderia ser afetada pelas flutuações dos valores brutos, enquanto seria menos afetada ressaltando-se as médias móveis, desde que esse "filtro" não leva a uma perda de informações demasiadamente importante.

Os valores das tendências correspondem à declividade da reta ajustada ao gráfico da precipitação anual pelo ano do calendário (por exemplo, 1962). Esses valores, por sua vez, foram submetidos ao teste de significância de Student com nível de significância de $10 \%$. O valor das tendências (positivo ou negativo), quando estatisticamente significativo, foi então considerado variável aleatoriamente distribuído no espaço. Finalmente, utilizando-se a teoria das variáveis regionalizadas (Matheron, 1965) e o método de interpolação da krigagem (Journel \& Huijbregts, 1997), traçou-se o mapa das tendências sobre a bacia do Rio Taperoá.

Ainda no eixo climático, o índice de aridez foi calculado. Para isto, a evapotranspiração potencial foi estimada através da fórmula de Hargreaves (1973) desenvolvida para a região:

$$
\mathrm{ETP}=\mathrm{F}(32+1,8 \mathrm{~T}) \mathrm{CU}
$$

donde ETP é a evapotranspiração potencial expressa em $\mathrm{mm} \mathrm{mês}^{-1}$, F é um fator empírico de evapotranspiração potencial, tabelado em função da latitude e do mês do ano, T é a temperatura do ar em ${ }^{\circ} \mathrm{C}$ e CU é outro coeficiente empírico que depende da umidade relativa do ar sob a forma:

$$
\mathrm{CU}=0,158(100-\mathrm{U}) 0,5
$$

sendo $\mathrm{U}$ a umidade relativa do ar, em porcentagem.

2. No eixo biológico analisou-se o tipo de vegetação e a sua evolução espacial, tomando-se por base a interpretação de fotografias aéreas de 1967 e imagens de satélite de 1990 e 1996 (Imagens TM Landsat 5, composição das bandas 3, 4 e 5).

3. No eixo hidropedológico foram levantados os diversos tipos de solo, aos quais foram associadas informações como profundidade, capacidade de campo, ponto de murcha e capacidade de água disponível por classe de solo. O balanço hídrico de Thornthwaite \& Mather (1957) foi realizado tendo em vista os valores de precipitação médios para os anos considerados normal, seco e chuvoso. Esta classificação seguiu o seguinte critério: o ano para o qual o total anual precipitado $\left(\mathrm{P}_{\mathrm{i}}\right)$ for inferior à precipitação média anual $(\mathrm{Pm}) \mathrm{da}$ série histórica diminuída da metade do desvio padrão $(\sigma)$ será considerado seco $\left(\mathrm{P}_{\mathrm{i}}<\mathrm{Pm}-0,5 \sigma\right)$; o ano para o qual o total anual precipitado $\left(\mathrm{P}_{\mathrm{i}}\right)$ for superior à precipitação média anual (Pm) da série histórica acrescida da metade do desvio padrão $(\sigma)$ é visto como chuvoso $\left(\mathrm{P}_{\mathrm{i}}>\mathrm{Pm}+0,5 \sigma\right)$; o ano que não se enquadra nas duas categorias anteriores é um ano dito normal.

4. No eixo socioeconômico foram analisados os dados dos censos relativos a população total, populações rural e urbana, pecuária (rebanhos bovino, caprino e ovino), lavoura permanente e temporária, pastagem natural e plantada e a produção de carvão vegetal, lenha e madeira em tora.

Como a área da bacia é muito extensa, os estudos relativos aos eixos biológico, hidropedológico e socioeconômico, foram realizados apenas nos municípios de Cabaceiras e São João do Cariri, uma vez que, além de apresentarem os menores índices pluviométricos anuais regionais, suas áreas são as maiores da bacia (respectivamente 18,2\% e 17,5\%).

\section{RESULTADOS E DISCUSSÃO}

\section{Fator climático}

A Figura 2 apresenta o mapa das tendências de pluviosidade anual na bacia do Taperoá (1932 a 1985). Observam-se duas manchas com tendências significativamente negativas, uma localizada no centro da bacia e a outra em direção noroeste.

Os resultados obtidos neste trabalho sobre a tendência da pluviosidade anual discordam daqueles encontrados por Conti (1995) nos municípios de: Cabaceiras, PB, São João do Cariri, PB, Equador, RN, e Parelhas, RN. Conti (1995) só considerou o período de observação até 1959 e, no caso de Cabaceiras, não descreveu os valores duvidosos entre os anos de 1946 a 1957; entretanto, Silva et al. (1998), analisando as tendências das precipitações anuais de inúmeros postos de toda a região Nordeste, encontraram resultados similares àqueles aqui apresentados. 


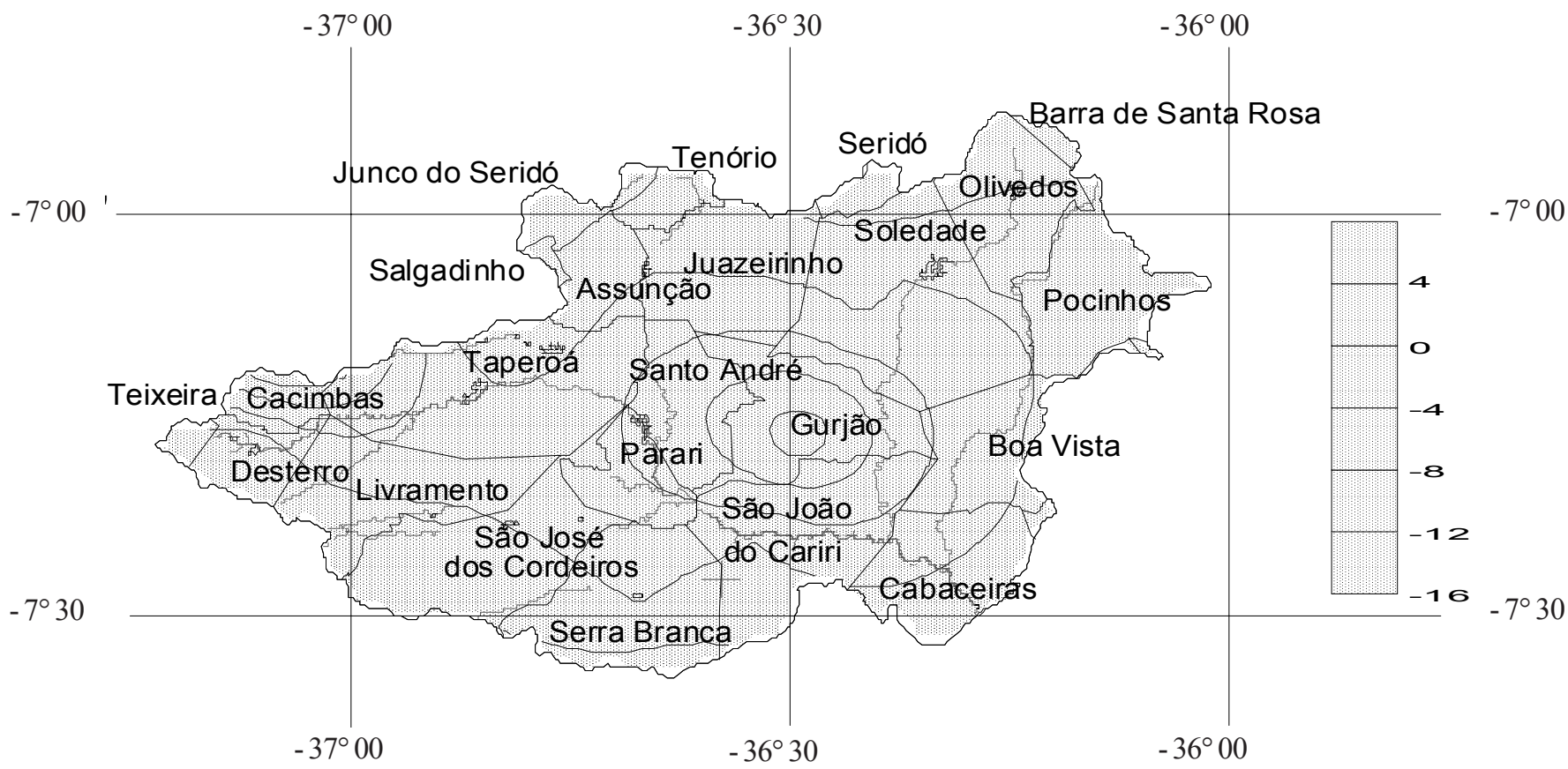

Figura 2. Mapa de tendência pluviométrica anual

A análise dos periodogramas das precipitações anuais registradas nos municípios de Cabaceiras e São João do Cariri, revelam ciclos de 36 anos e de 3 e 11 anos, respectivamente. Esses resultados convergem com os de diversos pesquisadores, entre eles Markham (1974), Jones \& Kearns (1976), Girardi \& Teixeira (1978), Nobre et al. (apud Conti, 1995) e Morettin et al. (apud Conti, 1995), destacando eles que não se verifica, de forma clara, a ocorrência de ciclicidade pluviométrica no semi-árido brasileiro.

Os coeficientes de variação da pluviosidade anual de cada posto variam entre $35 \%$ a $76 \%$, demonstrando que a dispersão em torno da média é muito alta, o que revela a vulnerabilidade climática regional, trazendo conseqüências marcantes para o quadro natural e econômico. Resultados semelhantes foram obtidos por Conti (1995) em 34 localidades da área semi-árida nordestina, e também por Silans et al. (1999) para toda a região semi-árida do estado da Paraíba. Este fenômeno de variabilidade alta na distribuição espacial e temporal da pluviosidade em regiões tropicais e subtropicais, é bastante comum, conforme ressaltam Planhol \& Rognon (1970) e Tarifa (1994); entretanto, chama a atenção neste trabalho, o nível das mesmas, o que deixa esse tipo de ambiente muito fragilizado perante as ações antrópicas e fortemente predisposto ao avanço da desertificação.

No tocante aos resultados da evapotranspiração potencial (ETP) para São João do Cariri, observou-se que é muito elevada (média anual de $1735 \mathrm{~mm}$ ), principalmente de setembro a março, quando as temperaturas são mais altas, e menores de abril a agosto, quando as temperaturas diminuem, enquanto os seus coeficientes de variação mensal e anual apresentam pequena variação: de 7,47 a $21,30 \mathrm{~mm}$ e de 29,61 a $45,87 \mathrm{~mm}$, respectivamente.

A partir da razão dos dados anuais da pluviosidade e da evapotranspiração potencial para São João do Cariri, obtevese um índice de aridez de 0,22 , classificando-se o município como semi-árido. Este valor se encontra próximo do limite para regiões consideradas áridas, o qual é igual a 0,20 , tendo sido esse mesmo aspecto observado em outras áreas do semi-árido nordestino, por Hargreaves (apud Ab’Sáber, 1994).

Um dos fatores principais responsáveis por esta severidade climática é o relevo, uma vez que a região se encontra a sotavento da Serra da Borborema e os ventos predominantes são os alísios, com direção Leste - Oeste ou Sudeste Noroeste. Também, os altos valores de evapotranspiração potencial são devidos aos altos índices de insolação.

\section{Fator vegetação}

De maneira genérica, toda a área em questão apresenta formação vegetal do tipo savana estépica denominada, no Brasil, caatinga, com estrato arbustivo dominante e alguns indivíduos arbóreos esparsos, além de larga concentração de cactáceas, diferindo apenas em sua densidade. Daí esta formação, a fim de análise espacial, ter sido classificada nos tipos: caatinga baixa e densa, caatinga baixa e rala e caatinga baixa e esparsa, ( Tabela 3 ).

Os dados da Tabela 3 demonstram predomínio da caatinga baixa e rala, o que reflete não apenas a severidade climática da região mas, também, a ocorrência de desmatamento para uso agropecuário do solo, o que torna esse tipo de vegetação degradada mais presente na área.

No que concerne à caatinga baixa e densa observou-se, em Cabaceiras, franca recuperação entre 1990 e 1996, o mesmo não ocorrendo em São João do Cariri, enquanto a caatinga

Tabela 3 . Evolução da vegetação - Caatinga (ha)

\begin{tabular}{lrrrrrrr}
\hline \multirow{2}{*}{ Tipo } & \multicolumn{3}{c}{ Cabaceiras } & & \multicolumn{3}{c}{ São João do Cariri } \\
\cline { 2 - 4 } & 1967 & 1990 & 1996 & & 1967 & 1990 & 1996 \\
\hline Baixa e densa & 8847 & 1932 & 5529 & & 30223 & 31112 & 28343 \\
Baixa e rala & 2730 & 49190 & 42634 & 6363 & 52990 & 45268 \\
Baixa e esparsa & 50770 & 7014 & 9621 & 70835 & 5810 & 23900 \\
\hline
\end{tabular}


baixa e esparsa, tipo mais aberto dessa vegetação, cresceu significativamente em São João do Cariri e ficou relativamente estável em Cabaceiras, no mesmo período. Esses números demonstram, portanto, uma diminuição mais intensa da densidade da caatinga no município de São João do Cariri, deixando-o mais propenso às manifestações da desertificação.

Vários pesquisadores têm demonstrado as relações existentes entre o desmatamento e a pluviosidade, como é o caso de Setzer (1946), Vianello (1976), Tullot (1991), Salati (1992), Leopold et al. (1997) e Nobre \& Gash (1997). Apesar do desmatamento em São João do Cariri ter sido maior que em Cabaceiras e a tendência da pluviosidade se ter mostrado negativa, ainda seria precipitado fazer uma relação inquestionável de causa e efeito, uma vez que a variabilidade espacial da tendência de precipitação, numa escala relativamente pequena, não permite esse tipo de associação sem que modelos climáticos de escalas regionais sejam aí desenvolvidos.

\section{Fator hidropedológico}

Conforme as informações da SEPLAN - PB (1997), nos municípios de Cabaceiras e São João do Cariri ocorrem 4 classes de solo: Brunos Não-Cálcicos (NC), Vertissolos (V), Litólicos $(\mathrm{Re})$ e Aluviais Eutróficos (Ae), todos eles em associação.

Em quase todas essas associações, estão presentes argilas de alta atividade coloidal que, apresentando grande capacidade de expansão, acabam por arrastar, horizontalmente, as sementes das plantas e as partículas do solo, intensificando a erosão e tornando mais difícil a recolonização desses ambientes. São solos bastante propensos à desertificação. Além disso, nessas associações também se encontram os solos Litólicos que, devido à pequena espessura, são altamente susceptíveis à erosão, além de apresentarem fortes limitações ao armazenamento de água. Quanto a este último aspecto, ou seja a capacidade de água disponível nos solos de Cabaceiras e São João do Cariri, esta é muito pequena nos Bruno Não-Cálcicos ( $\mathrm{NC}$ - textura média) e Litólicos ( $\mathrm{Re}$ - textura arenosa) e bem maior nos Vertissolos ( $\mathrm{V}$ - textura argilosa) e Aluviais Eutróficos (Ae-textura média), conforme demonstra a Tabela 4.

Apesar da elevada capacidade de água disponível dos solos Aluviais Eutróficos (Ae), estes se encontram, geralmente, associados aos Solonetz Solodizados (SS), apresentando problemas de drenagem e, sobretudo, acumulação de sais, e quando utilizados para irrigação podem comprometer intensamente os solos ainda não salinizados, como já verificado nessa região por Grabois et al. (1991). Os referidos solos também são encontrados nos leitos dos rios onde técnicas recentes de

Tabela 4 . Capacidade de água disponível por classe de solo*

\begin{tabular}{ccrrcc}
\hline $\begin{array}{c}\text { Classe } \\
\text { de solo }\end{array}$ & $\begin{array}{c}\text { Prof. } \\
(\mathrm{m})\end{array}$ & $\begin{array}{r}\mathrm{C} \mathrm{C} \\
(\%)\end{array}$ & $\begin{array}{r}\mathrm{PM} \\
(\%)\end{array}$ & $\begin{array}{c}\mathrm{DA} \\
\left(\mathrm{kg} \mathrm{dm}^{-3}\right)\end{array}$ & $\begin{array}{c}\mathrm{CA} \\
\left(\mathrm{m}^{3} \mathrm{ha}^{-1}\right)\end{array}$ \\
\hline $\mathrm{Ae}$ & 1,50 & 32,0 & 18,17 & 1,43 & 2288 \\
$\mathrm{~V}$ & 0,70 & 37,27 & 29,38 & 1,84 & 1200 \\
$\mathrm{NC}$ & 0,55 & 7,95 & 7,55 & 1,88 & 410 \\
$\mathrm{Re}$ & 0,25 & 3,17 & 10,69 & 1,58 & 125 \\
\hline
\end{tabular}

* Ae - Aluviais Eutróficos; NC - Brunos Não-Cálcicos; V - Vertissolos; Re - Litólicos; CC - Capacide de Campo; PM - Ponto de Murcha; DA - Desidade Aparente; CA - Capacidade de Água barragens subterrâneas foram implantadas com sucesso na região, pelo fato de acumularem água com evaporação limitada.

Em toda a bacia do Taperoá os solos Brunos Não-Cálcicos, Aluviais e Vérticos, são bastante representativos caracterizando-se, do ponto de vista agrícola, pelo pequeno potencial. Calculado o déficit hídrico anual pelo balanço hídrico de Thornthwaite \& Mather (1957) em anos classificados como chuvoso, normal e seco observou-se, para os anos chuvosos, que este é mais elevado; tal fato, aparentemente contraditório, é explicado pela maior concentração temporal das chuvas nos anos mais úmidos, o que implica num período mais longo de déficit hídrico, já que esses solos têm baixa capacidade de armazenamento de água.

\section{Fatores socioeconômicos}

A Tabela 5 revela a evolução dos fatores socioeconômicos mais importantes, no que diz respeito ao processo de desertificação, nos dois municípios considerados, durante o período de 1970 a 1995, em relação aos aspectos econômicos rurais, e de 1960 a 1996, quanto aos aspectos demográficos. Observa-se, nesta tabela, diminuição significativa da população nos dois municípios, mais acentuada em São João do Cariri de 17.633 habitantes em 1960 para 7.822 habitantes em 1996 e, também, uma forte migração da população rural para a área urbana, fenômeno este ligado às dificuldades da vida no campo, principalmente na época das secas que assolam a região, quando a população se ressente mais das condições financeiras e a produtividade dos solos, em parte degradados, fica mais comprometida.

Quanto à pecuária, predomina a criação de caprinos e ovinos, traço marcante na economia da bacia do Rio Taperoá devido a rusticidade e precocidade desses animais frente aos bovinos, alimentando-se predominantemente do pasto natural o qual, por sua má qualidade, resulta numa baixa capacidade de carga que permite apenas um animal em cada 12 a 15 ha. Esta capacidade, entretanto, é em muito excedida no baixo vale da

Tabela 5. Evolução dos fatores socioeconômicos (em \%)

\begin{tabular}{lcc}
\hline Fatores socioeconômicos & Cabaceiras & São João do Cariri \\
\hline Pecuária (1970-95) & & \\
Bovinos & 13,2 & 53,3 \\
Caprinos & 124,2 & 166,0 \\
Ovinos & 88,9 & 130,1 \\
Lavoura (1970-95) & & \\
Permanente & $-94,2$ & $-98,0$ \\
Temporária & $-55,8$ & 6,5 \\
Pastagem (1970-95) & & \\
Natural & $-54,6$ & $-22,3$ \\
Plantada & 55,9 & $-18,2$ \\
Madeira (1970-95) & & \\
Carvão & 91,8 & 175,0 \\
Lenha & $-92,3$ & $-70,8$ \\
Toras & 0,0 & 0,0 \\
População (1960-96) & & \\
Total & $-24,2$ & $-55,6$ \\
Urbana & 116,2 & 26,2 \\
Rural & $-44,7$ & $-66,6$
\end{tabular}

Fonte:IBGE-Censo Agropecuário/PB - 1970, 1980, 1985 e 1995

IBGE- Censo Demográfico/PB - 1960, 1970, 1980 e 1996 
bacia, onde se encontram os municípios aqui destacados, oscilando em torno de uma cabeça para cada 4 ha, segundo Grabois et al. (1991). Nessa área predomina o "sistema tradicional de caatinga", onde os animais vivem soltos no pasto natural, sem nenhum tipo de tratamento mais apurado, gerando baixa produtividade, além do superpastejo. Tal processo acaba dificultando a renovação da vegetação o que, por sua vez, gera a diminuição da biodiversidade e alterações hidrológicas e pedológicas (Warren \& Maizels, 1992). Isto se reflete nos valores indicados nas Tabelas 3 e 5 em que, para o município de São João do Cariri, um aumento considerável no rebanho de caprinos e ovinos é associado à diminuição das pastagens naturais ou plantadas e a um aumento muito significativo da vegetação de caatinga baixa e esparsa, entre os dois últimos censos.

Enquanto a pecuária se vem expandindo, a agricultura segue trajetória oposta, fato explicado pelo baixo nível econômico predominante na região dificultando, por exemplo, a existência de agricultura irrigada, e pela maior resistência do gado a um ambiente de clima severo; entretanto, essa mesma atividade criatória, da maneira como é feita, tem contribuído para a degradação das terras, gerando ainda mais incertezas para a população local.

Os dados da exploração de madeira para diversos fins, por sua vez, mostram claramente o quanto o uso desse recurso avançou, principalmente para a fabricação de carvão vegetal, utilizado na região para consumo doméstico e como fonte alternativa de renda. A produção de lenha vem diminuindo e a de toras não existe mais, levando-se a concluir que as árvores de maior porte da região vêm escasseando devido ao seu elevado consumo, particularmente na construção de cerca das propriedades rurais que têm de ser renovadas periodicamente; esses dados revelam a diminuição da qualidade das condições de vida no campo em razão da perda da capacidade produtiva existente nessas terras, aumentando a falta de perspectiva nas unidades familiares locais frente a essas adversidades, levandoos a um êxodo que se vem expandindo intensivamente.

\section{CONCLUSÕES}

1. Levando-se em conta a semi-aridez da região, associada à evolução da cobertura vegetal, aos fatores hidropedológicos e às diversas variáveis socioeconômicas estudadas neste trabalho, verificou-se a susceptibilidade potencial desta bacia à desertificação.

2. O processo de desertificação não ocorre de maneira generalizada por toda a área estudada, apresentando-se basicamente nos locais mais predispostos e de forma natural a esse processo, onde houve, e continua havendo, forte intervenção antrópica.

3. Os municípios de Cabaceiras e São João do Cariri, alvo maior das análises, apresentam várias áreas comprometidas com a desertificação.

4. Em São João do Cariri consta-se situação mais grave, tendo em vista a tendência decrescente de chuvas, o maior desmatamento, a presença de solos mais frágeis perante a degradação e o grande efetivo de caprinos e ovinos criados em bases pouco sustentáveis.
5. Os resultados dessa degradação já começam a se manifestar através da diminuição da biodiversidade e do aumento do êxodo rural.

6. Embora de caráter local, a possibilidade de expansão da desertificação na região e em outras próximas, é bastante forte devido a semelhança nos padrões de uso do solo associados à instabilidade ambiental aí existentes.

7. Em sua maioria, as ações dos proprietários de terras, sobretudo por falta de conhecimento e mesmo as políticas públicas implantadas nessa região com o objetivo de desenvolvê-la, pouco fizeram para a conservação dos seus recursos naturais, contribuindo para a aceleração dos processos de desertificação, uma vez que, embora o desenvolvimento sustentável seja aceito conceitualmente, ainda encontra uma série de dificuldades para se efetivar de maneira plena.

\section{LITERATURA CITADA}

Ab'Sáber, A.N. Problemática da desertificação e da savanização no Brasil intertropical. Geomorfologia, São Paulo, nº 53, 1977. $19 \mathrm{p}$.

Ab'Sáber, A.N. No domínio das caatingas. In: Caatinga: sertão/ sertanejos. Rio de Janeiro: Edições Alumbramento, 1994. 253p.

Aubreville, A. Climats, forêts et desertification de l'Afrique tropicale. Paris: Société d'Editions Géographiques Maritimes et Coloniales, 1949.351p.

Conti, J.B. Desertificação nos trópicos: Proposta de metodologia de estudo aplicada ao nordeste brasileiro. São Paulo: USP, 1995. 265p. Tese Livre-Docência

Convenção das Nações Unidas de Combate à Desertificação. Lisboa: Instituto de Promoção Ambiental, 1995. 94p.

Geiger, P.P.; Lyra, A.M.S.; Küffer, E.W.; Felicíssimo, P.L.P. Introdução à análise de séries temporais. Revista Brasileira de Geografia, Rio de Janeiro, v.36, n.4, p.81-108, 1974. 150p.

Girardi, C; Teixeira, L. Prognóstico do tempo a longo prazo. São José dos Campos: CTA/IAE, 1978. 60p.

Grabois, J.; Marques, M.I.M.; Silva, M.J. A organização do espaço no baixo vale do Taperoá: uma ocupação extensiva em mudança. Revista Brasileira de Geografia, Rio de Janeiro, v.53, n, 4, p.81-114, 1991.

Hargreaves, G.M. Monthly precipitation probabilities for Northeast Brazil. Logan: Utah State University, 1973. 166p.

IBGE - Instituto Basileiro de Geografia e Estatística. Censos agropecuários PB -1970, 1980, 1985 e 1995. Rio de Janeiro. 495p.

IBGE - Instituto Basileiro de Geografia e Estatística. Censos demográficos PB - 1960, 1970, 1980, 1991 e 1996. Rio de Janeiro. 610p.

IBGE - Instituto Basileiro de Geografia e Estatística. Classificação da vegetação brasileira, adaptada a um sistema universal. São Paulo, 1991. 123p.

Jacon, G. As precipitações anuais da região paraibana. Recife: SUDENE-DRN, 1982.97p.

Jones, R.M; Kearns, J.P. Fortaleza, Ceará: Brazil rainfall. Journal of Applied Meteorology, v.15, p.307-308, 1976. 520p. 
Journel A.G.; Ch. J. Huijbregts. Mining geostatistics. New York: Academic Press, 7 ed., 1997. 600p.

Koeppen, W. Climatologia: un estudio de los climas de la Tierra. México: Fundo de Cultura Economica. México, 1948. 478p.

Leopoldo, P.R.; Chaves, J.G.; Franken, W.K.; Vila Nova, N.A. Floresta tropical da Amazônia Central: possíveis efeitos do desmatamento no ciclo hidrológico da região. Ciência Geográfica, Bauru, ano III, n.7, p.4-6, 1997. 50p.

Markham, C.G. Apparent periodicities in rainfall at Fortaleza, Ceará, Brazil. Journal of Applied Meteorology, v. 13, p.176179, 1974. 230p.

Matheron G. Les variables régionalisées et leur estimation. Paris: Ed. Masson, 1965.330p.

Nobre, C.A; Gash, J. Desmatamento muda clima na Amazônia. Ciência Hoje, Saão Paulo, v.22, n.126, p.32-41, 1997.

Penman, H.L. The physical bases of irrigation control. In: Hort. Congr., 2, London, Royal Horticultural Society, 1953, p.913924. 1110p.

Planhol, X. de; Rognon, P. Les zones tropicales arides et subtropicales. Paris: Librairie Armand Colin, 1970. 487p.

Salati, E. A floresta e as águas. Ciência Hoje, Rio de Janeiro, v.3, n.16, p. 18-24, 1992. 160p.

SEPLAN - PB. Síntese do estudo de reconhecimento de solos em meio digital do Estado da Paraíba: Plano Diretor de Recursos Hídricos do Estado da Paraíba PDRH-PB. João Pessoa: Secretaria do Planejamento/PB, 1997. 49p.

Setzer, J. A distribuição normal das chuvas no Estado de São Paulo. IBGE, Revista Brasileira de Geografia, São Paulo, ano VIII, n. 1, p. 3-70, 1946. 170p.
Silva, V.P.R. da Correia A.A.; Coelho, M.S. Análise de tendência das séries de precipitação pluvial do Nordeste do Brasil. Revista Brasileira de Engenharia Agrícola e Ambiental, Campina Grande: v.2, n.1, p. 111-114, 1998.215p.

Souza, B.I. de. Contribuição ao estudo da desertificação na bacia do Taperoá. João Pessoa, Universidade Federal da Paraíba, 1999. 120p. Dissertação Mestrado

SUDENE. Dados pluviométricos mensais do Nordeste. Recife: Superintendência de Desenvolvimento do Nordeste, Série pluviometria 5, 1990.239p.

Tarifa, J.R. Alterações climáticas resultantes da ocupação agrícola no Brasil. Revista do Departamento de Geografia, Universidade de São Paulo, São Paulo, n.8, p.15-26, 1994.

Thornthwaite, C.W. Atlas of climatic types in the United States. Mixed Publication, 421, U.S. Department of Agriculture, Forest Service, 1941.250p.

Thornthwaite, C.W. Mather, J.R. Instructions and tables for computing potencial evapotranspiration and the water balance. New Jersey: Drexel Institute of Technogy., 1957. 180p.

Tullot, I.F. El hombre y su ambiente atmosférico. Madrid, Instituto Nacional de Meteorologia, 1991 p.132-144.

Vianello, R.L. Indícios de mudança climática causada por desmatamento - município de Juiz de Fora. Boletim Geográfico, Rio de Janeiro, v. 34 n. 251, p.139-150, 1976. 251p.

Warren, A.; Maizels, J.K. Mudança ecológica e desertificação. In: Desertificação: causas e consequências. Lisboa: Fundação Calouste Gulbenkian, 1992, p. 268-385. 678p. 